\title{
Mean Amplitudes of Vibration of the Halogen Molecules
}

\author{
Enrique J. Baran \\ Centro de Química Inorgànica (CEQUINOR/CONICET, UNLP), Facultad de Ciencias Exactas, \\ Universidad Nacional de La Plata, C. Correo 962, 1900 La Plata, Argentina \\ Reprint requests to Prof. Dr. E. J. B.; Fax: (54)02214259485; E-mail: baran@quimica.unlp.edu.ar \\ Z. Naturforsch. 58a, 36-38 (2003); received September 9, 2002 \\ Dedicated to Prof. Achim Müller on the occasion of his 65th birthday \\ Mean amplitudes of vibration of the halogen molecules $\mathrm{F}_{2}, \mathrm{Cl}_{2}, \mathrm{Br}_{2}$, and $\mathrm{I}_{2}$ have been calculated \\ from known spectroscopic data in the temperature range between 0 and $1000 \mathrm{~K}$. The results are \\ briefly discussed, and some comparisons with the results of the related diatomic interhalogen \\ molecules, as well as with experimental values obtained by electron diffraction experiments, are \\ made.
}

Key words: $\mathrm{F}_{2}, \mathrm{Cl}_{2}, \mathrm{Br}_{2}, \mathrm{I}_{2}$; Mean Amplitudes of Vibration; Bond Properties.

During the last years, we have performed systematic calculations on the vibrational properties of simple molecules and ions containing interhalogen bonds. Surprisingly, during our literature searches we found that detailed information on the mean amplitudes of vibration of the halogen molecules themselves ar not available. In the classic work of Cyvin [1] only a brief mention of these values for $\mathrm{Cl}_{2}, \mathrm{I}_{2}$, and ${ }^{79} \mathrm{Br}{ }^{81} \mathrm{Br}$, at two selected temperatures, are given. There is no information about $\mathrm{F}_{2}[1,2]$.

In order to fill this gap and to complement and extend our studies, we have now performed a calculation of the mean amplitudes of vibration of the four halogen molecules.

The calculations are relatively simple due to the fact that diatomic species present only one vibrational degree of freedom. The vibrational frequencies were taken from the book of Siebert [3]. They correspond to the gaseous $\mathrm{F}_{2}, \mathrm{Cl}_{2}$, and $\mathrm{Br}_{2}$ molecules and to a chloroformic solution of $\mathrm{I}_{2}$. These data, together with the corresponding force constants, calculated using the "two-masses model" [4], are presented in Table 1.

According to Kimura and Kimura [5]; mean-square amplitudes of vibration for a normal coordinate with

Table 1. Vibrational frequencies (in $\mathrm{cm}^{-1}$ ) and force constants (in mdyn/Å) for the halogen molecules.

\begin{tabular}{lll}
\hline Molecule $\left(\mathrm{X}_{2}\right)$ & $v(\mathrm{X}-\mathrm{X})$ & Force constant $\left(f_{\mathrm{X}-\mathrm{X}}\right)$ \\
\hline $\mathrm{F}_{2}$ & 892 & 4.46 \\
$\mathrm{Cl}_{2}$ & 558 & 3.25 \\
$\mathrm{Br}_{2}$ & 317 & 2.36 \\
$\mathrm{I}_{2}$ & 207 & 1.60 \\
\hline
\end{tabular}

one characteristic vibrational frequency can be calculated with the expression

$$
u_{\mathrm{XY}}^{2}=G_{\mathrm{XY}} \cdot \nabla_{1}
$$

where

$$
\begin{aligned}
& G_{\mathrm{XY}}=\mu_{\mathrm{X}}+\mu_{\mathrm{X}} \\
& \nabla_{1}=\left[h / 8 \pi^{2} v_{1}\right] \operatorname{coth}\left(h v_{1} / 2 k T\right)
\end{aligned}
$$

( $\mu_{\mathrm{X}}$ and $\mu_{\mathrm{Y}}$ are the reduced masses of the atoms $\mathrm{X}$ and $\mathrm{Y}$, in the present case being $\mathrm{Y}=\mathrm{X}$, and $v_{1}$ is the characteristic vibrational frequency of the $\mathrm{X}-\mathrm{X}$ bond, in $\mathrm{cm}^{-1}$ ).

Using these relations we have calculated the mean amplitudes of vibration for the four halogen molecules between 0 and $1000 \mathrm{~K}$. The obtained results are presented in Table 2, and the respective temperature dependencies are depicted in Figure 1.

The analysis of these results shows an unexpected behaviour at the lowest temperatures, as the molecules with the lowest vibrational frequencies and force constants show the lowest amplitude values. Only with increasing temperature the values show the expected trends, i.e. molecules with higher force constants and therefore stronger $\mathrm{X}-\mathrm{X}$ bonds present lower mean amplitudes of vibration. Such anomalies, usually denominated "low temperature anomalies", become always evident when the vibrations are dominated by mass effects rather than by the force constant effects (cf. for example [6, 7]. A similar 
Table 2. Calculated mean amplitudes of vibration (in $\AA$ ) of the four halogen molecules between 0 and $1000 \mathrm{~K}$.

\begin{tabular}{lllll}
\hline$T(\mathrm{~K})$ & $\mathrm{F}_{2}$ & $\mathrm{Cl}_{2}$ & $\mathrm{Br}_{2}$ & $\mathrm{I}_{2}$ \\
\hline 0 & 0.0446 & 0.0413 & 0.0365 & 0.0358 \\
100 & 0.0446 & 0.0413 & 0.0369 & 0.0377 \\
200 & 0.0446 & 0.0420 & 0.0404 & 0.0451 \\
298.16 & 0.0452 & 0.0442 & 0.0455 & 0.0527 \\
300 & 0.0452 & 0.0442 & 0.0455 & 0.0529 \\
400 & 0.0464 & 0.0472 & 0.0508 & 0.0601 \\
500 & 0.0482 & 0.0506 & 0.0558 & 0.0666 \\
600 & 0.0502 & 0.0540 & 0.0606 & 0.0727 \\
700 & 0.0524 & 0.0574 & 0.0650 & 0.0782 \\
800 & 0.0547 & 0.0606 & 0.0692 & 0.0835 \\
900 & 0.0570 & 0.0638 & 0.0733 & 0.0886 \\
1000 & 0.0593 & 0.0669 & 0.0771 & 0.0931 \\
\hline
\end{tabular}

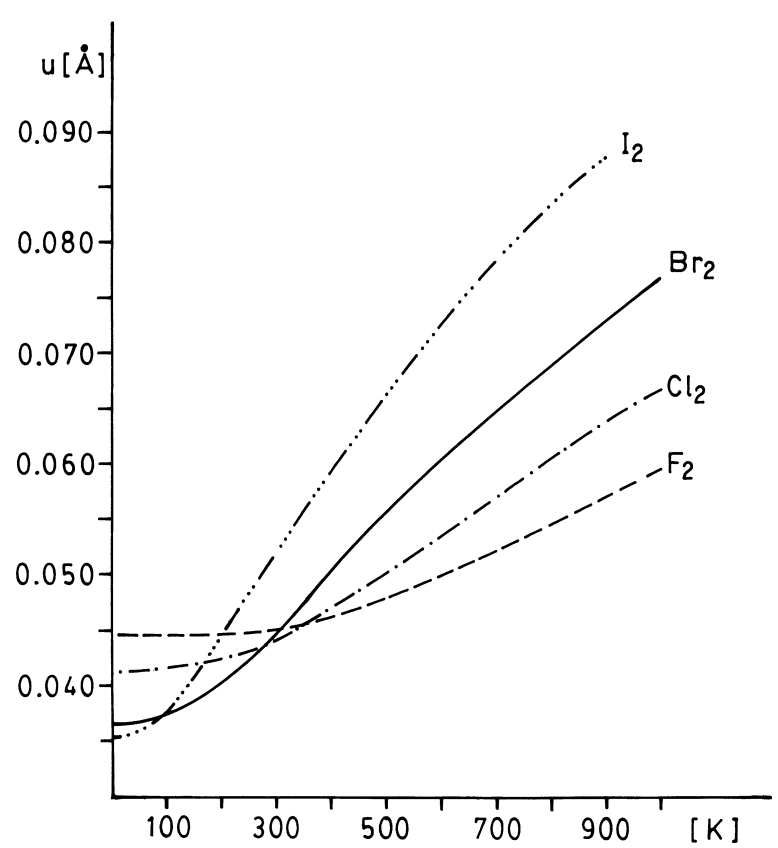

Fig. 1. Temperature dependence of the mean amplitudes of vibration of the four halogen molecules.

behaviour has been abserved in the case of the related diatomic XY interhalogen molecules [8].

In such cases, and at low temperatures, the higher masses of the vibrating units generate smaller vibrational amplitudes, solely as a consequence of a weight effect. Only at higher temperatures, the mean amplitudes of vibration become dominated mainly by the strength of the interatomic bonds, diminishing or canceling the mass effect. This fact is also clearly defined in the Theory of Molecular Vibrations, through the so-called "classical mean amplitudes of vibration", which only depend on the corresponding force constant $[1,6]$.

There exists another simple expression between the mean amplitudes of vibration and the force constants, which allows a wider insight into this peculiar problem $[9,10]$ :

$$
u_{\mathrm{XX}}^{2}=k T f_{\mathrm{XX}}^{-1}+\left[h / 64 \pi^{2} k T\right]\left(\mu_{\mathrm{x}}+\mu_{\mathrm{x}}\right) .
$$

This expression clearly shows that at low temperatures the second term can dominate the $u$-values, whereas with rising temperatures the first term acquires increasing impact, finally constituting the determinant factor.

A further comparison of the present results with those previously obtained for simple diatomic interhalogen molecules, using the same methodology of calculation [8], seems interesting. To support these comparisons, we present in Table 3 some relevant data for these molecules (force constants were taken from this work and from [8], whereas the other data are from [11].

As can be seen from this table, with only one exception (the pair $\mathrm{ICl} / \mathrm{Br}_{2}$, for which the force constants are practically identical) the bond lengths increase stepwise, with diminution of the respective force constants. Regarding the bond energies, the particularly low value of $F_{2}$ is well known and is discussed in all standard Inorganic Chemistry textbooks [12-14]. For all the other species, although the variations are not totally regular, a general trend becomes also evident, as the bond energies decrease in the same direction as the corresponding force constants.

Table 3. Force constants (mdyn/ $/ \AA$ ), bond energies (kcal/ $\mathrm{mol})$ and bond lengths (A) for the halogen and diatomic interhalogen molecules.

\begin{tabular}{llll}
\hline Molecule & Force constant & Bond energy & Bond length \\
\hline $\mathrm{F}_{2}$ & 4.46 & 37.0 & 1.418 \\
$\mathrm{ClF}$ & 4.36 & 59.5 & 1.628 \\
$\mathrm{BrF}$ & 4.07 & 59.6 & 1.756 \\
$\mathrm{IF}$ & 3.62 & 66.4 & 1.91 \\
$\mathrm{Cl}_{2}$ & 3.25 & 57.3 & 1.988 \\
$\mathrm{BrCl}$ & 2.80 & 51.6 & 2.138 \\
$\mathrm{ICl}$ & 2.38 & 49.7 & 2.321 \\
$\mathrm{Br} 2$ & 2.36 & 45.45 & 2.284 \\
$\mathrm{IBr}$ & 2.06 & 41.9 & $\left.(2.45)^{\mathrm{a}}\right)$ \\
$\mathrm{I}_{2}$ & 1.60 & 35.60 & 2.666 \\
\hline
\end{tabular}

a) Estimated with the Schomaker-Stevenson relation [11]. 
On the basis of the above trends it is possible to make also some comparisons between the mean amplitudes of vibration. Although the force constant of $F_{2}$ is by about $2 \%$ higher than that of $\mathrm{ClF}$, its bonding energy is appreciably lower. Consequently the mean amplitudes of vibration of $F_{2}$ are slightly higher in the full temperature range. Only above $600 \mathrm{~K}$ the values for both molecules become comparable. In agreement with their similar bonding energy, $\mathrm{BrF}$ and $\mathrm{ClF}$ present similar amplitudes, and those of BrF become again comparable with those of $F_{2}$ at temperatures above $600 \mathrm{~K}$.

The mean amplitudes of vibration of IF are markedly lower than those of $\mathrm{Cl}_{2}$ in the whole temperature range, in good agreement with its higher force constant and bonding energy. On the other hand, since $\mathrm{Br}_{2}$ and $\mathrm{ICl}$ present very similar bond properties one may expect similar mean amplitudes of vibration for both species, a fact that is better fulfilled at the highest temperatures, and the values between 800 and $1000 \mathrm{~K}$ are identical. At temperatures above $300 \mathrm{~K}$, the values of $\mathrm{Br}_{2}$ are always slightly higher than those of $\mathrm{BrCl}$, also in agreement with the somewhat stronger bond of the latter molecule.

Also the $1 \mathrm{Br} / \mathrm{l}_{2}$ pair fulfills the expectations derived from its bonding characteristics: the mean amplitudes of vibration of the halogen molecule are always higher than those of the diatomic interhalogen compound.

[1] S. J. Cyvin, Molecular Vibrations and Mean Square Amplitudes, Elsevier, Amsterdam 1968.

[2] S. J. Cyvin (Ed.), Molecular Structures and Vibrations, Elsevier, Amsterdam 1972.

[3] H. Siebert, Anwendungen der Schwingungsspektroskopie in der Anorganischen Chemie, Springer-Verlag, Berlin 1966.

[4] A. Fadini and F.-M. Schnepel, Schwingungsspektroskopie, Methoden, Anwendungen, G. Thieme Verlag, Stuttgart 1985.

[5] K. Kimura and M. Kimura, J. Chem. Phys. 25, 362 (1956).

[6] S. J. Cyvin, Kgl. Norske Videnskab. Selskabs Skrifter, Nr. 1 (1969).

[7] S. J. Cyvin and B. N. Cyvin, in S. J. Cyvin (Ed.), Molecular Structures and Vibrations, Elsevier, Amsterdam 1972 , pp. $255-260$.

[8] E. J. Baran, Z. Physik. Chem 255, 1022 (1974)

[9] A. Müller, B. Krebs, and C. J. Peacock, Z. Naturforsch. 23a, 1024 (1968).
Finally, it was also interesting to compare the now calculated values with those obtained from electron diffraction data, if available. For $\mathrm{Cl}_{2}$ the experimental values of $0.0446 \AA$ [15] and $0.044 \AA$ [16] obtained at $300 \mathrm{~K}$, are in excellent agreement with that calculated in the present work at the same temperature (0.0442 $\AA$ ). For $\mathrm{Br}_{2}$ a value of $0.045 \AA$ was found experimentally, also at $300 \mathrm{~K}$ [17], again in good agreement with that calculated here $(0.0455 \AA)$. In the case of $\mathrm{I}_{2}$ different values, obtained under different experimental conditions, were reported at $360 \mathrm{~K}$, ranging between 0.055 and $0.063 \AA$ [17]. We have also calculated the mean amplitude of vibration at the mentioned temperature, obtaining $0.0572 \AA$, in relatively good agreement with the electron diffraction data.

For $\mathrm{F}_{2}$ only the internuclear distance has been determined by means of electron diffraction experiments, without mentioning the value of the mean amplitude of vibration $[18,19]$.

\section{Acknowledgement}

This work was supported by the "Consejo Nacional de Investigaciones Científicas y Técnicas de la República Argentina”. The author is a member of the Research Career of this organism.

[10] A. Müller, E. J. Baran, and K. H. Schmidt, in S. J. Cyvin (Ed.), Molecular Structures and Vibrations, Elsevier, Amsterdam 1972, pp. 376-391.

[11] J. E. Huheey, E. A. Keiter, and R. L. Keiter, Inorganic Chemistry. Principles of Structure and Reactivity $4^{\text {th }}$ Ed. Harper-Collins, New York 1993.

[12] R. B. Heslop and K. Jones, Inorganic Chemistry. A Guide to Advanced Study, Elsevier, Amsterdam 1976.

[13] F. A. Cotton and G. Wilkinson, Advanced Inorganic Chemistry, $4^{\text {th }}$ Ed. J. Wiley, New York 1980.

[14] N. N. Greenwood and A. Earnshaw, Chemistry of the Elements, $2^{\text {nd }}$ Ed. Butterworth-Heinemann, Oxford 1997.

[15] L. S. Bartell and K. Kuchitsu, J. Phys. Soc. Japan 17 (Suppl. B-II), 20 (1962).

[16] S. Shibata, J. Phys. Chem. 67, 2256 (1963).

[17 I. L. Karle, J. Chem. Phys. 23, 1739 (1955)

18 L. O. Brockway, J. Amer. Chem. Soc. 60, 1348 (1938).

[19] M. T. Rogers, V. Schomaker, and D. P. Stevenson, J. Amer. Chem. Soc. 63, 2610 (1941). 